\title{
Research
}

\section{Improving Participatory Processes through Collective Simulation: Use of a Community of Practice}

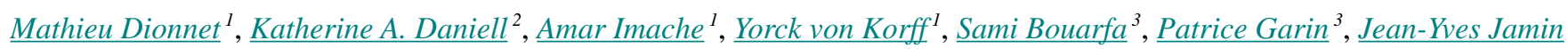 \\ ${ }^{4}$, Dominique Rollin $^{3}$ and Jean-Emmanuel Rougier ${ }^{1}$
}

\begin{abstract}
Stakeholder and public participation in natural resources management (NRM) is now widely accepted as necessary to achieve sustainable development outcomes. Yet, effective implementation of participatory processes necessitates wellcalibrated methods and tools, as well as carefully honed facilitation skills that are difficult to gain without practice. Practitioners and academics leading these processes are thus encouraged to better reflect on, prepare, and justify their interventions, before starting to work in the field with stakeholders. Our paper shows how a Simulation Community of Practice (SCoP) was set up to support improved participatory practice. The specificity of this community is that its members not only discuss planned participatory interventions, but also simulate these processes by adopting roles of future participants, and by working through the different steps of the workshop that will be later implemented in the field. The evaluation of our approach shows that individual and social learning of participants in the SCoP is developed, leading mainly to improved facilitator skills and to calibration of the participatory methods and tools being tested. A space is also provided for deepening reflection on the purposes of the participatory process and the values that guide these interventions. Our experience could provide a model for others around the world to set up their own SCoP to support participatory NRM practice. Further improvements to our SCoP and new ones could be made by enhancing the feedback mechanisms between the field sites and the community, in order to encourage more cumulative learning and to reinforce the members' interest, maintaining their involvement in the community over time.
\end{abstract}

Key Words: community of practice; natural resource management; public participation; role play; simulation

\section{INTRODUCTION}

Stakeholder and public participation in natural resources management (NRM) is now widely accepted as necessary to achieve sustainable development outcomes (United Nations 2002, United Nations Development Programme (UNDP) 2006). The reasons for this include: (1) that local people and other stakeholders have a democratic right to freedom of expression and to have a say in decision-making processes that will affect their lives and livelihoods, whether this is through the election of others to represent their views (representative democracy) or directly where they provide their own individual views (participative democracy) (United Nations Economic Commission for Europe (UNECE) 1998, Gaventa 2004); (2) in order to make decisions and implement many management strategies in areas where power and resources are dispersed, the resources and collective agreement of many stakeholders are commonly required (Daniell et al. 2010a); (3) stakeholder and local knowledge can be accessed and used in the development of better informed and more widely acceptable and implementable management strategies (Stern and Fineberg 1996, Fischer 2000); and (4) participation processes can lead to social learning and social cohesion (Webler et al. 1995, Bousquet et al. 2002, Ison et al. 2004, Pahl-Wostl and Hare 2004, HarmoniCOP 2005), which are necessary for coping with future challenges, such as biodiversity loss, climate change, and freshwater use (Rockström et al., 2009). There are now great numbers of examples of participatory resource management processes across the world that range in size from local processes with small groups to multi-level and multi-national endeavors (see Holmes and Scoones 2000, Etienne 2010, von Korff et al. 2012 for some collections of examples). Despite the growth of the capacity of many organizations and individuals to develop, manage, and implement such processes, practitioners generally face common issues and challenges when working in the field (Table 1).

Table 1 shows that many choices need to be made when designing or leading a participatory NRM process. These choices relate to aspects which include the objectives of the process, the selection of participants, the design and implementation of the process, the methods and tools, and the scope of evaluation. Table 1 also underlines the importance of facilitation skills for implementing these processes in the field. Consequently, two types of issues naturally arise for practitioners or academics leading participatory NRM processes: (1) how "good" decisions can be made related to participatory process design, implementation, and evaluation; and (2) how sufficient practical knowledge and skills can be developed in order to effectively facilitate the participatory process. Additionally, when working in the field with stakeholders, practitioners face many other social, ethical, political, and technical challenges (Table 1) due to the complexities and dynamic nature of local contexts, as well as to the uncertainties associated with impacts of actions and external factors. Some commonly experienced challenges or 
Table 1. Some key challenges related to participatory processes in NRM

\begin{tabular}{|c|c|c|}
\hline $\begin{array}{l}\text { Issues related to participatory } \\
\text { processes in NRM }\end{array}$ & Challenges related to these issues & $\begin{array}{l}\text { References to investigation of these } \\
\text { challenges }\end{array}$ \\
\hline $\begin{array}{l}\text { Problem and boundary } \\
\text { identification considered in NRM } \\
\text { analyses and planning }\end{array}$ & $\begin{array}{l}\text { NRM problems that require the set-up of a participatory process are } \\
\text { often complex, uncertain, and related to socio-political issues that do not } \\
\text { have predetermined solutions. Thus, their analysis requires a suitable } \\
\text { multi-disciplinary approach for managing wicked problems or "messes." }\end{array}$ & $\begin{array}{l}\text { (Ulrich 1983, Janssen and Goldsworthy } \\
\text { 1996, Rosenhead and Mingers 2001, Fischer } \\
\text { 2003, Khisty 2006) }\end{array}$ \\
\hline Participatory process design & $\begin{array}{l}\text { Designing a participatory process and choosing the appropriate methods } \\
\text { in a given NRM context depend on so many variables that it is difficult } \\
\text { to undertake them in a standardized and linear manner. Rather, it } \\
\text { requires a more open and adaptive process. } \\
\text { Identifying and deciding who participates is a delicate strategic question } \\
\text { with consequences for resource use, methods, equity, decision } \\
\text { acceptance, implementation capacity, etc. } \\
\text { Understanding participants' interests in participating in the process, } \\
\text { including potentially hidden motivations and agendas of stakeholders, } \\
\text { such as resistance to the process or to other stakeholders, is crucial to } \\
\text { support effective process design. }\end{array}$ & $\begin{array}{l}\text { (Stern and Fineberg 1996, Edelenbos 1999, } \\
\text { Beierle and Cayford 2002, Creighton 2005, } \\
\text { Daniell et al. 2010b, von Korff et al. 2010) }\end{array}$ \\
\hline $\begin{array}{l}\text { Development and use of } \\
\text { participatory methods and tools }\end{array}$ & $\begin{array}{l}\text { Participatory methods and tools need to be well calibrated and attractive } \\
\text { because stakeholders' time is limited. Tests are necessary before } \\
\text { working in the field. } \\
\text { Facilitation is crucial. The facilitator needs a range of social and } \\
\text { technical skills to handle a range of different situations, participants, and } \\
\text { attitudes. Skills are improved through practice. }\end{array}$ & $\begin{array}{l}\text { (Borrini-Feyerabend et al. 2000, Chambers } \\
\text { 2002, Lamers et al. 2010, Kaner 1996, } \\
\text { Schwartz 2002) }\end{array}$ \\
\hline $\begin{array}{l}\text { Ethical and political issues, } \\
\text { including the potential changes to } \\
\text { existing power structures incited } \\
\text { by the participatory NRM process }\end{array}$ & $\begin{array}{l}\text { The values that guide the intervention should be clarified before starting } \\
\text { the process, as they will directly affect its design. In particular, } \\
\text { understanding and coping with power asymmetries between participants } \\
\text { requires fine-tuning of the process and tools used. } \\
\text { The question of to what extent decision makers are willing to take into } \\
\text { account the stakeholders' opinions is often a key point of debate when } \\
\text { leading participatory processes. }\end{array}$ & $\begin{array}{l}\text { (Arnstein 1969, Taket 1994, Midgley 2000, } \\
\text { Freire 2001, Cahill et al. 2007, Sultana 2007, } \\
\text { Daniell et al. 2009, Barnaud et al. 2010) }\end{array}$ \\
\hline $\begin{array}{l}\text { Evaluation and outcomes of } \\
\text { participatory processes }\end{array}$ & $\begin{array}{l}\text { Participatory processes lead to various outcomes that are not always } \\
\text { planned. Evaluating, measuring the impacts, and learning from these } \\
\text { experiences require a large spectrum of analysis. }\end{array}$ & $\begin{array}{l}\text { (Rosener 1978, Guba and Lincoln 1989, } \\
\text { Syme and Sadler 1994, Webler 1995, } \\
\text { Estrella and Gaventa 1998, Rowe and Frewer } \\
\text { 2000, Brinkerhoff 2002, Daniell 2008, Jones } \\
\text { et al. 2009) }\end{array}$ \\
\hline
\end{tabular}

disruptive events for fieldwork can include: extreme climatic events, such as floods and droughts; political tensions and changes in local leadership; emergence of conflict; policy crises such as food shortages or trade sanctions; and privatization of public services. Practitioners and academics intending to lead participatory NRM processes in such contexts are, therefore, to be encouraged to better reflect on, prepare, and justify their interventions. This reflection is required before starting to work in the field with stakeholders to ensure the greatest chance of supporting knowledge development and positive change for local communities and their NRM systems.

Research has shown that professionals sharing similar concerns and wishing to resolve problems or improve their practice sometimes collaborate through "communities of practice" (Lave and Wenger 1991, Brown and Duguid 2000). These communities of practice $(\mathrm{CoP})$ support situated learning - a process through which knowledge is co-constructed-in order to improve participants' skills, but also to reinforce the meaning of their action (Lave and Wenger 1991).
This paper describes an experience in developing and using a CoP that aims to test participatory processes to be used for NRM before implementing them in the field with real stakeholders. As the approach used in this CoP relies on virtual experimentation, we have called it a "simulation community of practice" (SCoP). During these simulations, participants of the SCoP act out the roles of stakeholders, mobilizing their own field experience and knowledge of typical stakeholder perspectives, with the aim of questioning the experimental design of the participatory process and the capacity of the facilitator to deal with participant interactions. The SCoP, therefore, aims to help practitioners and researchers make strategic and well thought-out choices related to their participatory NRM processes and hone their facilitation skills.

In this paper, we explore to what extent the approach promoted through a SCoP may lead to outcomes that can support practitioners in the design and the implementation of participatory NRM processes. We first present the history and context of the SCoP, then a theoretical framework used to analyze our experiences. We then describe our research approach, clarify our research questions, and present the 
Fig. 1. Illustration of the simulation phase, where participants role-play a participatory workshop.
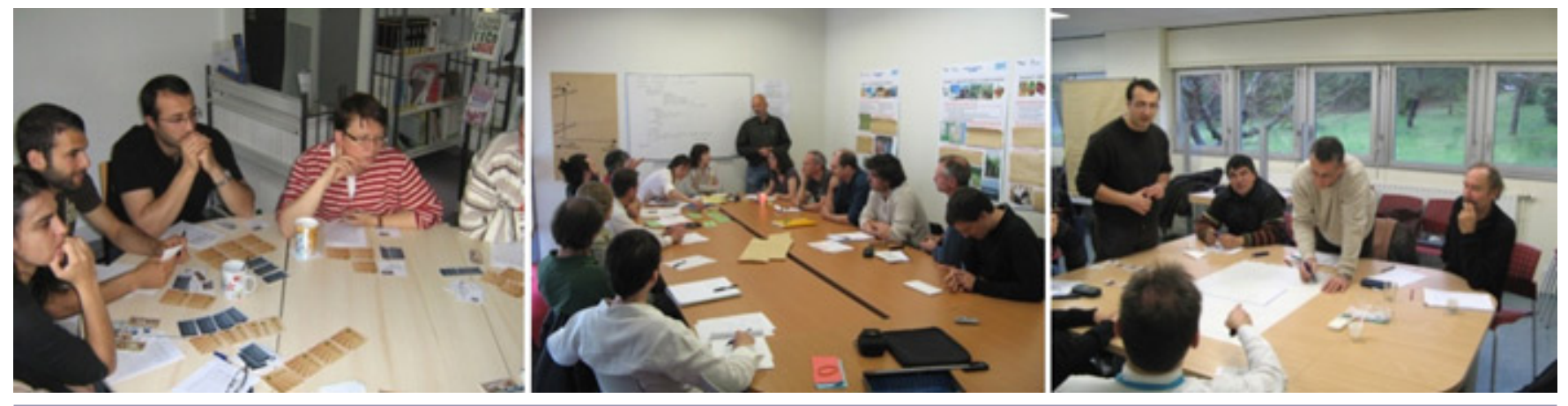

evaluation of the SCoP. Finally, we discuss to what extent such a CoP can help in coping with the key challenges related to participatory processes in NRM mentioned in Table 1, and outline some issues for future research and practice.

\section{HISTORY AND CONTEXT OF THE SIMULATION COMMUNITY OF PRACTICE}

We initiated the SCoP in response to problems we faced in various action-research projects (e.g., SIRMA, NEWATER, AQUASTRESS) in which we had to design, test, and evaluate new ways of involving stakeholders in NRM processes (a special feature has been published based these experiences: http://www.ecologyandsociety.org/issues/view.php?sf=43). As we were responsible for facilitating participatory workshops in the field with local stakeholders, we were looking for support to better prepare our interventions. Indeed, even if some of us had previous experience in this kind of intervention, the majority lacked competencies and experience in such work. Thus, we decided to meet and form ourselves into a community of practice dedicated to facilitation and participation. As we wanted the meeting sessions to treat the approaches and problem scope of the planned interventions rather than just discussing the methods, we quickly agreed that CoP participants would role-play the stakeholders' challenges and field site problems to be discussed. Thus, most sessions served to simulate workshops that one of the members had to later facilitate in a real-life setting. Most of facilitation and simulation methodologies trialed through the SCoP were based on previous research and practice experiences, mostly inspired by simulation and gaming techniques, as well as facilitation guides (Kaner 1996, Schwartz 2002, Dionnet et al. 2008). We attempted to provide a safe space for participatory process designers to investigate their facilitation competencies and to fine-tune potential use and impacts of their proposed tools, as well as to question the overall intervention philosophy and methodology.

Because the first members were mainly researchers working on participatory water management and irrigation issues, this theme maintained an important place in the SCoP. Other themes have nevertheless been addressed, such as fire risk management, natural area management, urban planning, and fisheries management. In fact, the SCoP does impose any restrictions on the themes addressed, as long as the focus of the sessions is related to participation issues for NRM.

Most of the members are researchers employed in the same French multidisciplinary research unit (UMR G-EAU), who lead action-research programs on participatory water management. But the SCoP also involves researchers from different organizations, as well as some professionals from the public and private sectors in charge of more operational interventions. In fact, three of the founders created a private consulting company (http://www.lisode.com/index.php/ english/home.html) and switched their work from the research unit to their own enterprise. Because they continue to collaborate with researchers of the UMR G-EAU and share research projects with them, they still pursue their involvement within the community. More details related to the structure and the main rules of the SCoP can be found in Appendix 1.

Apart from the first two sessions, which aimed to clarify the objectives and rules of the community, most of the sessions aimed to test and improve participatory tools such as facilitation methods and participatory set-up, including the use of simulation tools, role-playing games, participatory modeling exercises, and participatory forecasting. Some sessions have also been dedicated to the design of a participatory process or to its analysis, once it has been implemented in the field.

A "typical" session tends to have the following elements:

- An introduction, where the participants are introduced to each other and the session's agenda is presented;

- A presentation of the real-life context of the workshop to be facilitated;

- A simulation stage in which the session organizer facilitates participants' role-play through the planned workshop (Fig. 1); and 
- A debriefing period in which this particular simulated approach to facilitation and participatory methods is discussed.

The final discussions would usually not only address the specific workshop facilitation issues, but also more basic concerns related to the context of the project and process in which the workshop was embedded. Issues in this area of discussion commonly included: examining in which sequence different workshops of the planned participatory intervention are to be held and to what extent this plan seems to be a good idea; which stakeholders are planned to be involved (or ought to be involved) in the workshops; and whether more political or other type of support for the proposed intervention might be required.

Since its creation in 2007, 40 sessions have been organized (as of 8 August 2012), and more are being planned. The SCoP has more than 80 members. The success of this experience, but also some criticisms from colleagues, prompted us to raise questions about what we had created. Firstly, we wanted to understand to what extent aspects of participatory methodologies and processes could effectively be debated, designed, changed, or adapted for implementation by their organizers through a SCoP session involving participants from different backgrounds and stages of participatory practice experience. Secondly, we also sought to assess the other outcomes of the SCoP on both an individual participant level and at the group level, in order to understand what makes this community work and continue to thrive. In particular, we wanted to evaluate the importance of the basic principles of our community, such as simulation, feedback, multidisciplinarity, or openness and learning.

\section{THEORETICAL FRAMEWORK}

In this section, we propose a theoretical framework that will help us analyze our experience. We divide the framework into two main parts: one that looks at the "external effects" of the SCoP on participatory interventions; and a second that concentrates on the "internal effects" produced by our work in the SCoP.

As previously mentioned, the concept of a CoP was first proposed by Lave and Wenger (1991). The main objective of a CoP is to support situated learning for a group of people with a shared interest. Lave and Wenger (1991) stress that knowledge development not only takes place inside individuals' heads, but can also be co-constructed through a social process. This process includes two mechanisms: participation and reification. For Wenger (1998), the term "participation" is used to describe the experience of the participants who engage themselves in the social process. "Reification"-which is the process of transforming an abstraction into a concrete object-gives a shape to these experiences and includes the production of concepts, tools, symbols, stories, words, and meaning. In this context, reification should not be seen as the reduction of a complex experience to a simple element, but rather as the production of an intermediary object that helps the group members to coconstruct knowledge.

To better understand the meaning of Wenger's theory, it can be useful to refer to Piaget's knowledge construction theory (1977). To describe the process of cognitive change, Piaget (1977) proposes three stages. During the first stage, individuals discover a new problematic situation. They find themselves confronted with some type of contradiction: a conflict between what they do or think and the feedback they receive from their environment. This is the "destabilization" stage, where previous knowledge or behavior is being tested. During the second stage, individuals realize that they need to reappraise the way they think or act. This is the "awarenessraising" stage, which can lead to a trial-error process of evaluation of alternatives, or to individuals asking for help in order to find a solution. The third stage is dedicated to "abstraction." The individuals encapsulate what they have experienced in their consciousnesses and reorganize their operational plans. This is the stage of new knowledge construction.

Piaget's theory focuses on the psychology of individuals confronted with a problem they have to resolve. We can also use this theory to understand the exchanges and learning that take place in a social environment. Differences in points of views and interests can lead to an individual's destabilization. Exchanges within the group give participants the opportunity to become aware of the way they function, as individuals and as a group. Finally, because the group in a CoP shares common objectives, participants are encouraged to search for new operational plans. This collective construction creates both abstraction and reification, and supports the emergence of innovation-specifically, different ways of thinking or acting resulting from a change in understanding. Such a mutual learning situation is precisely described as social learning, as long as it becomes situated within a social unit such as a CoP (Reed and al. 2010). Therefore, we can establish a relationship between the first two stages of Piaget's cognitive change process (1977) and the participatory exchanges that take place in a CoP (Wenger 1998). Furthermore, Wenger (1998) stresses that these mechanisms of participation and reification not only produce individual and social learning, but also support "negotiation of meaning," which refers to "the process by which we experience the world and our engagement in it as meaningful" (Wenger 1998:53). Meaning is being negotiated in the sense that the process "constantly changes the situation to which it gives meaning and affects all participants" (Wenger 1998:54).

We have now outlined that a CoP typically supports individual and social learning and helps participants to collectively formalize the meaning of their actions, but to better analyze a 
CoP, we must also look at some of its other dimensions. According to Wenger (1998:2), a CoP defines itself through three dimensions: "What it is about-its joint enterprise as understood and continually renegotiated by its members; How it functions - the relationships of mutual engagement that bind members together into a social entity; What capability it has produced-the shared repertoire of communal resources (routines, sensibilities, artifacts, vocabulary, styles, etc.) that members have developed over time." In addition, it seems important to look at the concrete outcomes produced by this process, in particular to what extent people engaged in a CoP apply what they have learnt or experienced in the real world.

Therefore, we can distinguish two distinct foci when evaluating a $\mathrm{CoP}$ :

(1) Internal effects within the group:

- Assessing participant and organizer perceptions of the usefulness of a CoP;

- Determining how participants interact within it;

- Investigating the learning processes, both individual and social, produced by their interaction, and which outcomes they produce (formalizing knowledge about something, negotiating meaning about an action...); and

(2) External effects:

- Determining what concrete changes or improvements these learning processes produce related to the participatory processes' design and implementation.

\section{METHODOLOGY}

The theoretical framework described above helps focus our analysis on the questions we raised about the SCoP. As described before, our SCoP is based on the way people interact, and consequently, the way the learning processes occur. In our SCoP, these interactions are mainly produced by physically simulating the NRM participatory processes to be tested. This is carried out through highly interactive sessions where participants "play out" the proposed participatory processes. We call the SCoP meetings "sessions," the people who organize the sessions (and who will later implement these participatory processes in the field) "organizers," and the people who participate in these sessions "participants." These are not to be confused with the "stakeholders" who take part in the "workshops" we later implement in the field.

The first challenge of the SCoP evaluation was to identify concrete elements related to the way the sessions were organized in order to assess if they effectively supported the improvement of the design and implementation of the participatory NRM processes, and thus help to cope with the challenges identified in Table 1. As this evaluation was carried out after the fact, we did not have the opportunity to make note of these interactions during these sessions, but we were able to investigate some of their consequences. Two types of data were used for this purpose: the individual session reports written by the organizer, which provide a summary of the session, including information of the debriefing (these are publicly available at www.particip.fr); and the feedback from session participants.

As we (the nine authors of this paper) are particularly active members of the SCoP, we also took this evaluation process as a further chance to develop learning between us and with the other members about our experience, as well as to be open to adjusting the SCoP based on this learning. This follows Guba and Lincoln's (1989) view of evaluation, which takes place as an intervention that is likely to impact and alter the object being evaluated. In this optic, we thus decided to lead a participatory evaluation program that aimed to mobilize all of the SCoP members involved in the first 20 sessions (from 2007.01.12 to 2010.05.03) in order to reflect on our collective practices and to gain further insights into this "simulation community of practice" approach and its wider impacts.

The analysis started with a review of the reports of the first 20 sessions, which provided us with a clear overview of their scope, including: who participated; which participatory methods and tools had been tested; which processes were discussed; and some of the main results from the sessions. We then undertook a two-part evaluation program. We first organized a debriefing session-to which all members were invited, and 16 participated (the report of the session is available at http://www.particip.fr) - in order to brainstorm and investigate the results and outcomes so far obtained throughout the life of the community, and to investigate the two main focus areas of interest highlighted in the theoretical framework. In particular, we debated what the organizers and participants perceived to be the usefulness of the sessions. We also took some time to discuss the strengths and weaknesses of the community, as well as desirable improvements such as enhanced learning outcomes. Secondly, and based on the results of the debriefing session, we conducted an e-mail survey with all participants and organizers of the SCoP sessions to assess their perceptions about the SCoP sessions.

In this survey, each session's organizers were asked to assess five propositions that aimed to clarify their perceptions about the main outcomes of the sessions that they had organized. The first propositions were related to the co-testing - through simulation_of a specific participatory method/tool, phrased as follows (direct translation from French): Did the session allow you to: (1) calibrate and improve the method/tool; (2) train yourself to facilitate use of the method/tools; (3) gain knowledge/experience from the participants about the method/tool. The next propositions were related to the future participatory process implementation in the field and phrased as follows: the session allowed you to: (4) clarify the objectives and the hypotheses behind the process; (5) work through 
Fig. 2. Detailed results of the SCoP evaluation survey for participants $(\mathrm{P})$ and organizers $(\mathrm{O})$. The numbers on the bars are the number of respondents replying to each answer category.

Did the session allow you to:

participate in an interdisciplinary exchange $(P)$

participate in an interdisciplinary exchange $(\mathrm{O})$

discover a new field site $(P)$

experiment with a participatory method $(P)$

experiment with a participatory method $(O)$

participate in a community which shares the same

questions ( $P$ )

participate in a community which shares the same

questions $(\mathrm{O})$

spend some enjoyable time together $(P)$

spend some enjoyable time together $(O)$

calibrate and improve the method/tools (O)

train myself to facilitate the method/tools (O)

gain knowledge/experience from the participants about

the method/tool $(\mathrm{O})$

clarify the objectives and the hypothesis behind the

process $(\mathrm{O})$

work through organizational management issues (O)

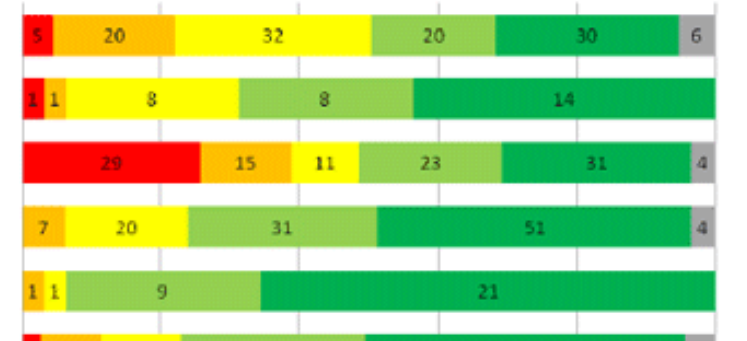

Possible answers:

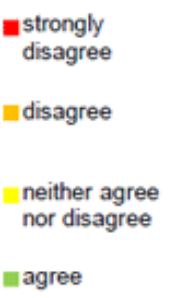

agree

Estrongly agree

no answer organizational management issues (contact people, potential participants, finding necessary resources, potential blockages, and opportunities, etc.).

Five other secondary propositions were assessed by all participants (including the organizers), to understand some of the more subjective outcomes of the SCoP, which were phrased as follows: Did the session allow you to: (1) participate in an interdisciplinary exchange; (2) discover a new field study site; (3) experiment with a participatory method; (4) participate in discussions with a community that shares the same interests; (5) spend some enjoyable time together. For all 10 propositions, qualitative comments could also be added to each response.

Participants of the SCoP provided their responses to the propositions on a five-point Likert scale, with these responses being able to be classified either more positively (strongly agree, agree) or more negatively (disagree, strongly disagree). The option of a moderate choice (neither agree nor disagree) was also provided. In addition, participants could answer, "I don't remember" or "I don't know," which have been grouped in the "moderate response" category in the analyses. The intention of the questionnaire was not to yield statistically interpretable results but rather to show broad trends in the perceptions of the respondents and to compare the relative proportions of participants benefitting or not in certain ways from their involvement in the SCoP.

\section{RESULTS}

We received 145 responses to the 207 questionnaires we sent (according to the number of sessions attended, each participant or organizer could answer several questionnaires). Out of these 145 responses, 32 were provided by the organizers of the sessions. This equates to a $70 \%$ response rate for all participants and a $97 \%$ response rate for session organizers. The results of this survey, outlined in Fig. 2, are organized following the aforementioned research propositions, which address issues associated with internal effects (i.e., what participants perceive the usefulness of the SCoP to be, the learning processes) and outputs (i.e., the decisions/changes that the SCoP produced related to the design and implementation of participatory NRM processes). As previously outlined, no intentional observation was carried out to understand the way people interact within the SCoP during the simulation phase to explain the two learning stages presented by Wenger in 1998 (participation and reification), 
but we draw a parallel between the results elicited from the brainstorming, debriefings, and survey and these concepts in the discussion section. Finally, we further investigate the meaning of the results of the survey by presenting some of the qualitative comments the participants added, as well as some further elements of context that could help readers better interpret the responses provided here.

\section{What is the perceived usefulness of the SCoP?}

From Fig. 2, it is clear that most organizers found that their session helped them better calibrate their method/tools. It also shows that the session provided a training opportunity in the use and facilitation of their method/tools, including gaining feedback from participants on them. To a slightly lesser extent, but still in the majority of cases, organizers were also supported in working through organizational management issues and/or clarifying the objective and hypotheses behind their processes.

It is also evident from the results that the sessions represented a generally pleasant experience, as almost all organizers and most of the participants agreed that they had spent some enjoyable time together during the SCoP sessions (this proposition received the maximum average of positive answers across all participants). For example, one participant indicated in the 2007.01.12 session dedicated to sharing ideas about facilitation, "I remember a period of discussion in a friendly atmosphere with a group of people who were convinced of the necessity to experiment with various participatory approaches and methods." It was also evident that the exchanges produced through the role-playing parts of the sessions were broadly appreciated by participants and were just one of the motivations for some returning to participate in the SCoP. For example, one participant who was involved in a role-playing activity around a participatory tool for groundwater management in the 2007.04.27 session wrote that it was a: "Very interesting session that motivated me to come back. I was interested in the problems raised in the field site as much as the methods used."

However, digging deeper into the results and summary of participation from the report analysis and qualitative evaluation comments, we saw that approximately half of the people who participated in the first 20 sessions of the SCoP (39 out of the 68) only attended one session, and another sixth (12 out of 68) only participated in two sessions (Appendix 1). There were multiple reasons that came out from these participants' evaluations for this weak implication in the SCoP, including that: some participants were interested in one topic only or came along to support a particular organizer; some participants left Montpellier; and some were not interested in the role-playing process used. Therefore, there are multiple reasons for the perceived usefulness or not of the $\mathrm{SCoP}$ for different participants, which will be further reflected upon in the discussion.

\section{What Outcomes Did the Learning Processes Have on the SCoP Organizers' and Participants' Understanding, Knowledge, and Skills?}

\section{Learning by simulation}

As can be seen from the results in Fig. 2, the majority of organizers agreed that SCoP sessions supported them in training themselves to use their methods or tools before their real workshops with stakeholders in the field. It is considered that this is the direct consequence of the role-playing exercise in the sessions during which the organizers put themselves in the facilitator role. This allows the organizers to test their participatory methods and workshop program with participants who role-play the future stakeholders.

For the participants, the sessions seemed useful to many of them for discovering new participatory methods (Fig. 2). Again, the role-playing participatory process simulation setup allows the objectives of the organizer's process to be understood, along with the scope of the intervention and the way the participatory method functions. It appears from the results that if participants stated that they had learned about new methods, then they seemed to learn less about the field sites. Apart from the organizers of the sessions who did not answer this question (as they inevitably knew their site), many participants did not seem to discover anything new about the field sites; although this is, perhaps, due in some cases to the participants working in the same projects on the same field sites as the session organizer. Also, some sessions did not necessarily present specific field sites (three sessions).

However, the high level of negative answers could also demonstrate that in some sessions less time was dedicated to the presentation of the context compared with the participatory method simulation. Further information on this aspect of the workshop evaluation was gained through the qualitative responses associated with this proposition, where one participant indicated in the follow-up evaluation for the 2009.03.24 session, which focused on testing a multistakeholder approach for irrigation management in Algeria, that: "I also wanted to have feedback from the field, to follow this experience in order to see how the stakeholders appreciated the workshop." The participant was referring to the advice that had been given during the SCoP session and how it would have been useful to have a follow-up later on about how the adapted process had worked out in the field. From such a response, it was clear that the participant was seeking to learn more about the field study site and the impact of the SCoP session on the field work. This means that there is probably room for improvement in the SCoP regarding this aspect; in particular, that greater feedback could be provided to the community following the real workshops, in order for participants to better understand the field site process, and whether their advice was useful or potentially detrimental in the real stakeholder context. Such feedback would also allow 
further reflection related to what extent the role-playing simulation sessions reflected the realities of the real workshops.

\section{Learning together}

The exchanges that occur during the role-playing simulation exercises and debriefing periods clearly allowed most organizers to obtain advice about the methods used. Thus, we can surmise that SCoP sessions allowed the organizers to learn from the participants' experiences. Much of this learning most probably occurred during the debriefing phase, when participants reflect openly to the group on what they think has functioned or not and why, and provide advice to the organizers on how they might improve the participatory method or process. However, how this learning process occurs is a question that could also be further studied through ongoing evaluation in later SCoP sessions. Additionally, it was noted in the debriefing evaluation for the SCoP that some participants' interests extend beyond an instrumental use of the community, instead acknowledging that a reciprocal relationship was entered into by many of the organizers and participants, who at different times reversed their roles and benefitted from the others' involvement in their different projects and field sites. This relational aspect of learning together is most likely a strong reason for maintaining ongoing interactions with the community.

Looking at the interdisciplinary knowledge exchanges and what this means for learning together, the results show that only approximately half of all the participants and organizers agreed they took part in an interdisciplinary exchange. As outlined in the section, "History and Context of the Simulation Community of Practice," the community was initially convened by researchers working mainly in the field of participatory water management. Although various disciplines were always present during the sessions, they were not necessarily equally represented. In particular, some social scientists were often more interested in the "why" questions related to the development of the participatory processes than in the "how" related to their design and implementation, which was often the key interest of the natural scientists or engineers (see below). As discussed in the SCoP evaluation debriefing, these exchanges and disciplinary cultural differences only came into play in some sessions, so for many participants the potential lack of conflict and need to step out of their comfort zones may have led some of them to disagree that there had been interdisciplinary exchange in the sessions. Such insights require deeper investigation in future research.

The last outcome is related to the clarification (and perhaps modification) of the organizers' values and positioning related to the participatory process. From the survey, over half of the organizers concluded that the sessions allowed them to clarify the objectives and assumptions underlying their processes. However, some of the other organizers were more cautious in agreeing with this proposition, as demonstrated by the high level of moderate or neutral answers. In fact, this was one of the key topics debated during the brainstorming session. For some participants, it was of great interest to debate such aspects within the SCoP. For example, in the 2009.04.24 session dedicated to participatory scenario approach testing for groundwater management in France, different participants stated: "This session was a chance to discuss the relevance of the process. There were interesting debates on the [organizer's] positioning, the approach, etc." and "The session allowed researchers to make explicit what they were expecting from the participatory process and to test their hypotheses by discussing them." Therefore, this session seemed to allow researchers to negotiate the meaning of their intervention. But this was not necessarily a desirable use of time for all participants. For example, another participant in the same session found this kind of discussion was undesirable, as in their mind the principal objective of the SCoP session was to help them to improve their method: "I didn't spend a very enjoyable time, because the objectives of the session were not shared, and finally I was disappointed by the results in comparison to my expectations" [which were related to methodological aspects, and not to research hypotheses and positioning]. How the SCoP might better take into account variance in participants' expectations is further analyzed later in the discussion.

\section{What Concrete Changes or Improvements Did these Learning Processes Produce Related to the Participatory Processes' Design and Implementation?}

One of the main consequences of the learning experiences previously highlighted relates to the calibration or modification of the participatory methods and tools being tested. In some cases, the methods were completely changed; in others, it was simply better calibrated. As noted in the session summary reports, these changes or improvements were typically related to very practical aspects of the participatory methods, such as the timing in workshops, the supports used (charts, photographs, short texts...), the logistical layout of the space/room to be used or the facilitation rules, the phasing of the different steps, etc.

The learning experiences also had an impact on the organization of some practical aspects of the participatory process implementation. In some cases, the sessions gave the organizers the opportunity to make important decisions, such as deciding whether or not to use the proposed method/tools in their planned workshops; deciding when, how, and with whom the process was to be run; and deciding to ask for the support of a professional facilitator. In addition, there were times following certain SCoP sessions when members of the community initiated collaborative activities with others in the community to support the transfer of some methods or tools, and to work through some of their previous workshop design experiences to further enhance social learning and knowledge transfer. 


\section{DISCUSSION}

As stressed in the introduction, practitioners and researchers face different issues and key challenges when designing and implementing participatory processes for natural resources management (NRM). Many difficult questions are raised due to the potential political and ethical implications of their participatory interventions. Moreover, facilitators of these processes often require training and practice to improve their facilitation skills. This means that both collective reflection on the implications of their proposed work and practical training are necessary for practitioners and researchers to succeed when facing these challenges. Consequently, in Table 2 , we interpret these results from the SCoP evaluation in relation to the key challenges outlined in Table 1 . In each case, the information from the session reports, debriefing session, and evaluation survey were used to establish to what extent (great impact, reasonable impact, little impact, no discernible impact) the SCoP has supported organizers and participants in responding to these challenges.

\section{Importance of Simulation for Learning}

Through the SCoP, a particular form of social interaction is played out by participants and organizers through the simulation process, potentially reproducing some of the possible interactions that could occur in "real life" during participatory workshops involving stakeholders. This "learning in doing" is central to Lave and Wenger's (1991) theory of situated learning. By developing such a process, we do not intend to predict the results of the workshop, but rather aim to improve or work on a number of challenges related to the participatory processes, such as: calibrating the methods and tools; training facilitators and improving their skills; clarifying the logic that guides the intervention; and working through organizational management issues of the process (Table 2).

One common critique of the type of approach used in the SCoP is that the participants in the sessions are unable to reproduce the behavior of stakeholders because of differences in their knowledge and experiences. In fact, one of the key differences between the SCoP session simulations and reality is related to the stakeholders' room to maneuver, as, when the participants (of the SCoP sessions) are given a role, they are unable to predict whether they are underestimating or overestimating the different possible behaviors of real stakeholders. In our sessions, we have experiences of both, and practicing facilitators have found it useful to have learned about how to handle potential extreme behaviors.

There is some evidence, as shown by the results, that even if we are unable to closely reproduce reality, the simulations produce a number of outcomes that aid learning about how to handle situations that are likely to occur in a participatory workshop (e.g., questioning the objectives of the workshop, asking for the rules to be changed, not understanding what is asked, disruptive behavior). Facilitators are confronted with these possible situations and follow a situated learning process as described by Wenger (1998). In our case, this learning process typically takes place with the following steps that match with what Wenger (1998) describes as "participation": (1) the organizers simulate the facilitation of a participatory workshop; they discover that something does not work when negative feedback is received from their social environment (composed of the participants playing the stakeholders' roles); (2) The organizers realize that they need to reappraise the way they facilitate the workshop, or more generally to improve their methods or tools; (3) if the organizers are able to do so, they lead a trial-and-error process, or ask for help until they find an improved solution. The last step of the learning process that occurs within a SCoP session matches Wenger's (1998) "reification" concept: (4) the organizers run a debriefing of the experience with the participants and formalize some insights from the session, including about their facilitation skills, the methods or tools that were used, and the scope or organizational logistics of the process.

\section{Open Feedback and Negotiation of Meaning}

The SCoP is not the only community in existence that tests or reflects upon forms of participatory research intervention to enhance field work. For example, participatory or companion modelers often test their methods before using them in the field (Etienne 2010), although these are generally tested with students or close colleagues in their institution. Other institutions who use intervention research methods, for example, to improve organizational production or to resolve management issues in businesses, have developed processes with sounding-board committees (Berry 1995) to help researchers better understand their actions and impacts in their field work. Committee meetings, like the SCoP sessions, typically take place away from the field site, although membership of the sounding-board is clearly defined.

The SCoP, therefore, varies in distinct ways from the practices of some of the existing participatory research intervention groups. In particular, the simulations of participatory processes take place in an open community and produce an ongoing process of social learning for the organizers and participants in regular attendance. This means that the SCoP carries potentially higher levels of gain, but also risks. Specifically, the organizers are obliged to reveal their methods and tools, and their way of facilitating a participatory workshop, to a potentially wide range of people who have significant knowledge, interest, and experiences in participatory processes in NRM. The participants experience and provide constructive criticism and advice about how the workshop and methods can be improved. But this feedback often goes beyond practical aspects. The common diversity of participants in terms of their interdisciplinary backgrounds and institutional affiliations (e.g., researchers, consultants, public servants) seems to favor the need for organizers to make 
Table 2 Evaluation of the SCoP's impact related to the challenges of participatory processes in NRM. To what extent this SCoP helps to produce specified outcomes that respond to these challenges are interpreted as follows: $+++=$ great impact; $++=$ reasonable impact; $+=$ little impact; + - $=$ no discernible impact.

\section{Key challenges related to participatory processes in NRM Outcomes of the SCoP that respond to these challenges}

Implementing a multidisciplinary approach to understand + and manage wicked problems or "messes"

The SCoP brings people together from various backgrounds, disciplines, and levels of experience, who jointly discuss the context and problem scope of interventions, simulate a proposed participatory method, and take part in debriefing discussions. Indeed, the organizers "open" their methodologies to the other participants who can criticize them according to their own perspectives. Because this takes place early in the intervention process, the organizers are more prone to reflect on their own boundary judgments and be able to adapt their

Designing the participatory process and choosing the appropriate methods

Identifying and deciding who participates

Understanding participants' interests in participating

Calibrating participatory methods and tools for workshops

Developing facilitator skills

Clarifying the values that guide the intervention, including in relation to power asymmetries

Clarifying to what extent decision makers are ready to take into account the stakeholders' opinions

Identifying various outcomes of the process that are not always planned methodologies according to participants' analyses and joint discussions.

$+/++$ (depending on the "room to maneuver")

The sessions allow the organizers to address strategic issues about what to do, why and how, with participants external to their projects. First, organizers benefit from participants' experiences and can thus minimize the risk of making poor decisions in their processes. Next, sensitive questions can be addressed in a constructive way, allowing the organizers to confront their logic of intervention with others' perceptions, and thus reinforce or adapt it. Finally, a space of creativity is created, allowing organizers and participants to generate new ideas to improve the processes being discussed. All of these aspects allow the "co-engineering" (Daniell et al. 2010b) of the organizer's process to be supported.

$+$

During the simulation phase of the sessions, it is sometimes possible to see if some specific interests are missing from the substance of the participatory methods or if the process potentially goes against any of the targeted stakeholders' interests. Ways of managing these issues and proposing how stakeholders might be selected can then be worked through. $++$

By simulating the roles of the future stakeholders, the potential motivations, interests and hidden agendas of participants are sometimes brought into the open. This allows the facilitator to learn about possible participant reactions to the process or needs for the workshop. $+++$

By testing the methods and tools, it becomes obvious to what extent they work for the desired purpose. At the very least, the simulation process provides some good insights into what needs to be improved and how this might be done. Participants can provide their expertise to the organizers and thus contribute to and support, using their own practical experiences, the calibration of the methods and tools.

$+++$

By simulating the facilitation of the workshop, the organizers are able to train themselves in the use of the participatory method/tools, as well as improve their facilitation skills in general by managing possible complicated behavior of the stakeholders (e.g., questioning the objectives of the workshop or those of the process, questioning the legitimacy of the facilitator, creating trouble, being distracted, arguing).

$+$

By playing the roles of the stakeholders, the participants can more easily debate the values behind the intervention, as they directly experience the method and its impacts. The discussions during the debriefing can then address the objectives of the intervention, helping the organizers to clarify their hypotheses and positioning related to the field site and stakeholders. + -

This is a difficult issue to address during the SCoP sessions, as this kind of information generally goes beyond participants' understanding of the case study. However, it is common for participants to probe organizers with questions on this topic in an attempt to drive critical reflection and mutual understanding.

$+$

By playing the roles of stakeholders, participants can gauge the possible impacts that the process can have on individuals and the group involved in the simulation (e.g., feelings of discomfort, levels of learning, conflict management, connections created between participants). Participants can also suggest means for evaluating the field intervention or for testing evaluation procedures in the sessions. 
explicit many of the assumptions underlying their participatory intervention, including those associated with: the dynamics of ecosystem functioning; the theoretical suppositions of the proposed participatory process; and the advantages and disadvantages of the practical means chosen to carry out the process in the field. Deeper reflection and discussion on political and ethical issues also take place, such as the competing interests of the organizers and the stakeholders. By entering into such discussions, organizers and participants negotiate the meaning of their action, which sometimes leads the organizers to revisit the objectives of the participatory process, and therefore, adapt the way the workshop will be initiated and designed.

Such openness and feedback sometimes prove too intrusive for the organizers. As mentioned in the results, some organizers initially only have the objective of testing their tools, but in fact, their whole approach is questioned by the participants, as many of them see this aspect as equally important for the success of the participatory NRM process intervention. This appears to show that the community needs to more carefully explain the "rules of the game" to both current and potential organizers and participants, including that all questions on the approach and tools can be raised so they can decide whether or not to participate. Despite the occasional difference in objectives, the majority of the organizers appeared willing to participate in such an open process, seemingly because they felt that they could trust the other community members to support them, and found that the SCoP process, even if difficult, was worthwhile.

\section{Grounded Speculation: the SCoP's Capacity to Support Cumulative Learning}

According to Green's studies (Green 2002, Green and Armstrong 2011), role-playing and role-thinking help improve the accuracy of forecasts in conflict-ridden situations. Similar approaches are also developed to forecast or learn about: political problems (Toth 1988, Duke and Geurts 2004); organizational issues (Schelling 1961); or common-pool resources management (Etienne 2010). There is a common idea behind all these approaches: by "standing in the other person's shoes," it becomes easier to predict the results of these people's interactions in a given situation. This can be carried out to inform decisions, to learn how to handle future situations, or to develop adapted evaluation procedures. The simulations that take place in the SCoP have the same objective: we aim to imagine and learn how to handle the interactions that will potentially occur during the participatory workshops. However, compared with most of these aforementioned approaches, we conduct simulations over time with many of the same participants, which might support cumulative learning.

Step-by-step, the participatory tools, methods, and workshop processes we test, as well as the discussions and ideas we share, create an informal common reference framework. Each new session is built upon the last one, and benefits from the insights gained in previous sessions. For example, we frequently mobilize previous sessions' results in our discussions. We also see that it becomes increasingly easier for participants to project themselves into the stakeholders' roles during the simulations, and for potential organizers to participate in the simulation and testing process. Therefore, we can hypothesize that the community is able to support cumulative learning among the members who regularly participate in the SCoP sessions.

However, this cumulative learning could be reinforced. Although participants often enjoy the experience of discovering new participatory tools and methods, there were several demands for hearing about what occurred in reality with stakeholders in the field. They were especially interested in knowing to what extent their advice had been followed and how the process worked out in relation to this, in particular linked to extra political ramifications and ethical dilemmas organizers ended up facing in the field when implementing the process. Without such capacity for feedback on the effectiveness and consequences of participatory processes and the procedures supporting their design, some SCoP participants showed little interest in attending sessions regularly. Therefore, we consider that for the many participants who only attended one or two SCoP sessions, and for future new participants, it may be particularly important to clarify in the sessions when and how feedback from the field will be reported to the community, providing them with an enticement to remain engaged in the community.

This feedback from the field, linked with being able to collectively debrief over the usefulness of the previous sessions, could also help to construct a deeper understanding of a range of cases and strengthen cumulative learning. It could also help the SCoP participants give meaning and form to this learning, including through the development of common principles and frameworks for designing, testing, implementing, and evaluating participatory processes for NRM. Such an enhanced SCoP process would lead to the much stronger production of "actionable knowledge" (Hatchuel 2005), or knowledge that can be directly used in practice.

\section{CONCLUSIONS}

According to Wenger's (1998) definition, the social structure that is described in our paper can be considered as a community of practice. Indeed, it is a joint enterprise of people who want to improve their practices; its functioning allows participants and facilitators to simulate future situations, exchange information about their experiences, and generate new ideas; it produces individual and social learning; and it supports the development of a common reference framework. Throughout the paper, we have presented and assessed a number of challenges related to the design and implementation of 
participatory processes in NRM, which constitute the main concerns for our SCoP.

As we described, the way we organize our sessions, mainly through collective role-playing simulation and debriefing of participatory processes, supports concrete learning mechanisms - participation and reification-and helps participants negotiate the meaning of their actions. However, due to the follow-up nature of much of our research, we suggest that further research, in particular through carefully designed formative or ongoing evaluation (Daniell 2012), is required to deepen knowledge of this aspect of the SCoP and other similar communities. Moreover, we suggest that further improvements to the SCoP could be made by enhancing the feedback mechanisms between the field sites and the community. This could encourage more cumulative learning about the effects of the decisions taken following the SCoP sessions on the field site and stakeholders, and how participatory practice could be readjusted in future NRM interventions based on this knowledge.

Our experience shows that it seems useful to simulate participatory processes related to NRM issues within a community of practice in order to improve them. Such processes are implemented in complex and uncertain contexts, where classical analytical methods are insufficient to guide the field interventions (Rosenhead and Mingers 2001). As stressed by Janssen and Goldsworthy (1996), multidisciplinary research is essential for addressing NRM issues. This means that group work is necessary in order to confront divergent ideas in a constructive way, which is what the SCoP outlined in this paper attempts to support. Moreover, the evaluation of the practices and underlying attributes of the SCoP through the beginning phase of its lifetime have shown that it supports many other aspects that need to be considered when organizing a participatory process. For example, it was typically successful in supporting the calibration and use of participatory methods and tools, including the honing of facilitators' skills, improving the design of participatory processes, and reflecting on ethical and political issues linked to the real-life interventions in the field. For these reasons, we suggest that our community could provide a model for other practitioners around the world to set up their own SCoP-like groups to support participatory NRM practice on a broader scale.

Responses to this article can be read online at: http://www.ecologyandsociety.org/issues/responses. $\mathrm{php} / 5244$

\section{LITERATURE CITED}

Arnstein, S. R. 1969. A ladder of citizen participation. Journal of the American Planning Association 35(4):216-224.

Barnaud, C., A. van Paassen, G. Trébuil, T. Promburom, and F. Bousquet. 2010. Dealing with power games in a companion modelling process: lessons from community water management in Thailand highlands. Journal of International Agricultural and Extension Education 16:55-74. http://dx. doi.org/10.1080/13892240903533152

Beierle, T. C., and J. Cayford. 2002. Democracy in practice: public participation in environmental decisions. Resources for the Future, Washington, D.C., USA.

Berry, M. 1995. Research and the practice of management: a French view. Organization Science 6:104-116. http://dx.doi. org/10.1287/orsc.6.1.104

Borrini-Feyerabend, G., M. T. Farvar, J. C. Nguinguiri, and V. A. Ndangang. 2000. Co-management of natural resources: organising, negotiating and learning-by-doing. GTZ and IUCN, Kasparek Verlag, Heidelberg, Germany.

Bousquet, F., O. Barreteau, P. D’Aquino, M. Etienne, S. Boissau, S. Aubert, C. Le Page, D. Babin, and J.-C. Castella. 2002. Multiagent systems and role games: collective learning processes for ecosystem management. Pages 248-285 in M. A. Janssen, editor. Complexity and ecosystem management: the theory and practice of multi-agent systems. Edward Elgar Publishers, Cheltenham, UK.

Brinkerhoff, J. M. 2002. Assessing and improving partnership relationships and outcomes: a proposed framework. Evaluation and Program Planning 25:215-231. http://dx.doi. org/10.1016/S0149-7189(02)00017-4

Brown, J. S., and P. Duguid. 2000. Balancing act: how to capture knowledge without killing it. Harvard Business Review: May-June issue. [online] URL: http://lymabe. edublogs.org/files/2007/04/balancing-act.doc

Cahill, C., F. Sultana, and R. Pain. 2007. Participatory ethics: politics, practices, institutions. ACME: An International EJournal for Critical Geographies 6:304-318.

Chambers, R. 2002. Participatory workshops: a sourcebook of 21 sets of ideas and activities. Earthscan, London, UK.

Creighton, J. L. 2005. The public participation handbook: making better decisions through citizen involvement. JosseyBass, San Francisco, California, USA.

Daniell, K. A. 2008. Co-engineering participatory modelling processes for water planning and management/Co-ingénierie des processus de modélisation participative pour la planification et la gestion de l'eau (2 Volumes). Australian 
National University, Canberra, Australia, and AgroParisTech, Montpellier, France.

Daniell, K. A. 2012. Co-engineering and participatory water management: organisational challenges for water governance. Cambridge University Press, Cambridge, UK. http://dx.doi. org/http://dx.doi.org/10.1017/CBO9780511998072

Daniell, K. A., C. Mazri, and A. Tsoukiàs. 2010a. Real world decision-aiding: a case of participatory water management. Pages $125-150$ in D. Rios Insua, and S. French, editors. $e$ Democracy: a group decision and negotiation perspective. Springer, Dordrecht, The Netherlands.

Daniell, K. A., I. White, N. Ferrand, I. S. Riborova, P. Coad, J.-E. Rougier, M. Hare, N. Jones, A. Popova, P. Perez, and S. Burn. 2010b. Co-engineering participatory water management processes: theory and insights from Australian and Bulgarian interventions. Ecology and Society 15(4): 11. [online] URL: http://www.ecologyandsociety.org/vol15/iss4/art11/

Daniell, K. A., I. White, and D. Rollin. 2009. Ethics and participatory water planning. Pages 1476-1487 in Proceedings of the 32nd Hydrology and Water Resources Symposium: "H2009", 30 November-3 December 2009, Newcastle, Australia.

Dionnet, M., M. Kuper, A. Hammani, and P. Garin. 2008. Combining role-playing games and policy simulation exercises: an experience with Moroccan smallholder farmers. Simulation and Gaming 39:498-514. http://dx.doi. org/10.1177/1046878107311958

Duke, R. D., and J. L. A. Geurts. 2004. Policy games for strategic management. Dutch University Press, Amsterdam, The Netherlands.

Edelenbos, J. 1999. Design and management of participatory public policy making. Public Management Review 1:569576.

Estrella, M., and J. Gaventa. 1998. Who counts reality? Participatory monitoring and evaluation: a literature review. IDS Working Paper No. 70. Institute of Development Studies, Brighton, UK.

Etienne, M., editor. 2010. La modélisation d'accompagnement : une démarche participative en appui au développement durable. Editions Quae, Versailles, France.

Fischer, F. 2000. Citizens, experts, and the environment. Duke University Press, Durham, North Carolina, USA.

Fischer, F. 2003. Reframing public policy: discursive politics and deliberative practices. Oxford University Press, Oxford, UK. http://dx.doi.org/http://dx.doi.org/10.1093/019924264X.001.0001

Freire, P. 2001. Pedagogy of freedom: ethics, democracy, and civic courage. Rowman and Littlefield, New York, New York, USA.
Gaventa, J. 2004. Triumph, Deficit or Contestation? Deepening the 'deepening democracy' debate. Seminar on Deepening Democracy Governance and Civil Society Unit, Ford Foundation, 3 December 2004, Rio de Janeiro.

Green, K. C. 2002. Forecasting decisions in conflict situations: a comparison of game theory, role-playing, and unaided judgement. International Journal of Forecasting 18:321-344. http://dx.doi.org/10.1016/S0169-2070(02)00025-0

Green, K. C., and J. S. Armstrong. 2011. Role thinking: Standing in other people's shoes to forecast decisions in conflicts. International Journal of Forecasting 27:69-80. http://dx.doi.org/10.1016/j.ijforecast.2010.05.001

Guba, E. G., and Y. S. Lincoln. 1989. Fourth generation evaluation. Sage Publications Inc, Newbury Park, California, USA.

HarmoniCOP. 2005. Learning together to manage together: improving participation in water management. Harmonising Collaboration Planning Project, Europe. [online] URL: http:// www.harmonicop.uni-osnabrueck.de/HarmoniCOPHandbook. pdf

Hatchuel, A. 2005. Towards an epistemology of collective action: management research as a responsive and actionable discipline. European Management Review 2:36-47. http://dx. doi.org/10.1057/palgrave.emr.1500029

Holmes, T., and J. Scoones. 2000. Participatory environmental policy processes: experiences from North and South. IDS working paper 133. Institute of Development Studies, Brighton, UK.

Ison, R. L., P. Steyaert, P.P. Roggero, B. Hubert, and J. Jiggins, editors. 2004. The SLIM (social learning for the integrated management and sustainable use of water at catchment scale). Final report. Prepared for the European Commission, FP5, Europe.

Janssen W., and P. Goldsworthy. 1996. Multidisciplinary research for natural resource management: conceptual and practical implications. Agricultural Systems 51(3):259-279. http://dx.doi.org/10.1016/0308-521X(95)00046-8

Jones, N. A., P. Perez, T. G. Measham, G. J. Kelly, P. D'Aquino, K. A. Daniell, A. Dray, and N. Ferrand. 2009. Evaluating participatory modeling: developing a framework for cross-case analysis. Environmental Management 44:1180 1195. http://dx.doi.org/10.1007/s00267-009-9391-8

Kaner S. 1996. Facilitator's guide to participatory decisionmaking. New Society Publishers, Gabriola Island, British Columbia, Canada.

Khisty, C. J. 2006. A fresh look at the systems approach and an agenda for action: peeking through the lens of Churchman's 
aphorisms. Systemic Practice and Action Research 19:3-25. http://dx.doi.org/10.1007/s11213-005-9001-5

Lamers, M., B. Ottow, G. Francois, and Y. von Korff. 2010. Beyond dry feet? Experiences from a participatory watermanagement planning case in the Netherlands. Ecology and Society 15(1): 14. [online] URL: http://www.ecologyandsociety. org/vol15/iss 1/art14/

Lave, J., and E. Wenger. 1991. Situated learning: legitimate peripheral participation. Cambridge University Press, Cambridge, UK. http://dx.doi.org/10.1017/CBO9780511815355

Midgley, G. 2000. Systemic intervention: philosophy, methodology, and practice. Kluwer Academic / Plenum Publishers, New York, New York, USA. http://dx.doi.org/ http://dx.doi.org/10.1007/978-1-4615-4201-8

Pahl-Wostl, C., and M. Hare. 2004. Processes of social learning in integrated resource management. Journal of Community and Applied Social Psychology 14:193-206. http://dx.doi.org/10.1002/casp.774

Piaget, J. 1977. Recherches sur l'abstraction réfléchissante. Presses Universitaires de France, Paris, France.

Reed, M. S., A. C. Evely, G. Cundill, I. Fazey, J. Glass, A. Laing, J. Newig, B. Parrish, C. Prell, C. Raymond, and L. C. Stringer. 2010. What is social learning? Ecology and Society 15(4): r1. [online] URL: http://www.ecologyandsociety.org/ vol15/iss $4 /$ resp1/

Rockström, J., W. Steffen, K. Noone, Å. Persson, F. S. Chapin, III, E. F. Lambin, T. M. Lenton, M. Scheffer, C. Folke, H. J. Schellnhuber, B. Nykvist, C. A. de Wit, T. Hughes, S. van der Leeuw, H. Rodhe, S. Sörlin, P. K. Snyder, R. Costanza, U. Svedin, M. Falkenmark, L. Karlberg, R. W. Corell, V. J. Fabry, J. Hansen, B. H. Walker, D. Liverman, K. Richardson, P. Crutzen, and J. A. Foley. 2009. A safe operating space for humanity. Nature 461:472-475. http://dx.doi.org/10.1038/461472a

Rosenhead, J., and J. Mingers, editors. 2001. Rational analysis for a problematic world revisited: problem structuring methods for complexity, uncertainty and conflict. Second edition. Wiley, Chichester, UK.

Rosener, J. B. 1978. Citizen participation: can we measure its effectiveness? Public Administration Review 38:457-463. http://dx.doi.org/http://dx.doi.org/10.2307/975505

Rowe, G., and L. J. Frewer. 2000. Public participation methods: a framework for evaluation. Science, Technology and Human Values 25:3-29. http://dx.doi.org/10.1177/016224390002500101

Schelling, T. C. 1961. Experimental games and bargaining theory. World politics 14:47-68. http://dx.doi.org/10.2307/2009555
Schwartz, R., 2002. The skilled facilitator: a comprehensive resource for consultants, facilitators, managers, trainers, and coaches. Jossey-Bass, San Francisco, California, USA.

Stern, P. J., and H. V. Fineberg, editors. 1996. Understanding risk: informing decisions in a democratic society. National Academy Press, Washington, D.C., USA.

Sultana, F. 2007. Reflexivity, positionality and participatory ethics: negotiating fieldwork dilemmas in international research. ACME: An International E-Journal for Critical Geographies 6:374-385.

Syme, G. J., and B. S. Sadler. 1994. Evaluation of public involvement in water resources planning: a researcherpractitioner dialogue. Evaluation Review 18:523-542. http:// dx.doi.org/10.1177/0193841X9401800501

Taket, A. 1994. Undercover agency?-Ethics, responsibility and the practice of OR. Journal of the Operational Research Society 45:123-132.

Toth, F. L. 1988. Policy exercises: objectives and design elements. Simulation and Gaming 19:235-255. http://dx.doi. org/10.1177/0037550088193001

Ulrich, W. 1983. Critical heuristics of social planning: a new approach to practical philosophy. Haupt Academic Publishers, Berne, Switzerland.

United Nations. 2002. Report of the World Summit on Sustainable Development, Johannesburg, South Africa. 26 August-4 September 4, 2002. A/CONF.199/20. United Nations, New York, New York. [online] URL: http://www. johannesburgsummit.org/html/documents/summit_docs/131302 wssd report reissued.pdf

United Nations Development Programme (UNDP). 2006. Beyond scarcity: power, poverty and the global water crisis. Human development report 2006. UNDP, New York, New York, USA.

United Nations Economic Commission for Europe (UNECE). 1998. Convention on access to information, public participation in decision-making and access to justice in environmental matters. Aarhus Convention, 25 June 1998. United Aarhus, Denmark. [online] URL: http://www.unece. org/env/pp/documents/cep43e.pdf

von Korff, Y., K. A. Daniell, S. Moellenkamp, P. Bots, and R. M. Bijlsma. 2012. Implementing participatory water management: recent advances in theory, practice, and evaluation. Ecology and Society 17(1): 30. http://dx.doi. org/10.5751/ES-04733-170130

von Korff, Y., P. d'Aquino, K. A. Daniell, and R. Bijlsma. 2010. Designing participation processes for water management and beyond. Ecology and Society 15(3): 1. 
[online] URL: http://www.ecologyandsociety.org/vol15/iss3/ $\underline{\operatorname{art1/}}$

Webler, T. 1995. "Right" discourse in citizen participation: an evaluative yardstick. Pages 35-86 in O. Renn, T. Webler, and P. Wiedemann, editors. Fairness and competence in citizen participation: evaluating models for environmental discourse. Kluwer Academic Publishers, Dordrecht, The Netherlands.

Webler, T., H. G. Kastenholz, and O. Renn. 1995. Public participation in impact assessment: a social learning perspective. Environmental Impact Assessment Review 15:443-463. http://dx.doi.org/10.1016/0195-9255(95)00043E

Wenger, E. 1998. Communities of practice: learning, meaning, and identity. Cambridge University Press, Cambridge, UK. 


\section{APPENDIX 1. Structure and rules of the Simulation Community of Practice (SCoP)}

\section{Structure of the community}

As shown in Fig. A, The SCoP is structured as followed: First, 3 participants form a core group. They take care of the different tasks related to the community's life: helping the members to organize the sessions, updating the website, etc. Secondly, there are 5 regular participants, probably as they are both interested in the topics of the sessions and the life of the community itself, as they have participated in more than half of the sessions (that is to say almost certainly on more topics than those of prior interest to them). Thirdly, 21 participants participated in at least 2 sessions, and are probably more interested in the topics than the community itself (as they probably do not come if the topics do not directly interest them). Fourthly, 39 participants only attended one session and so do currently not seem interested in following the community through time. However, the number of participants registered on the website of the community (62), who voluntary asked to be informed about the sessions, as well as the specificity of some members (living in foreign countries) should balance this last assumption. Some participants are probably also waiting for the opportunity to be involved in more ongoing projects with feedback from the field, rather than once-off testing events, as mentioned in the evaluations.

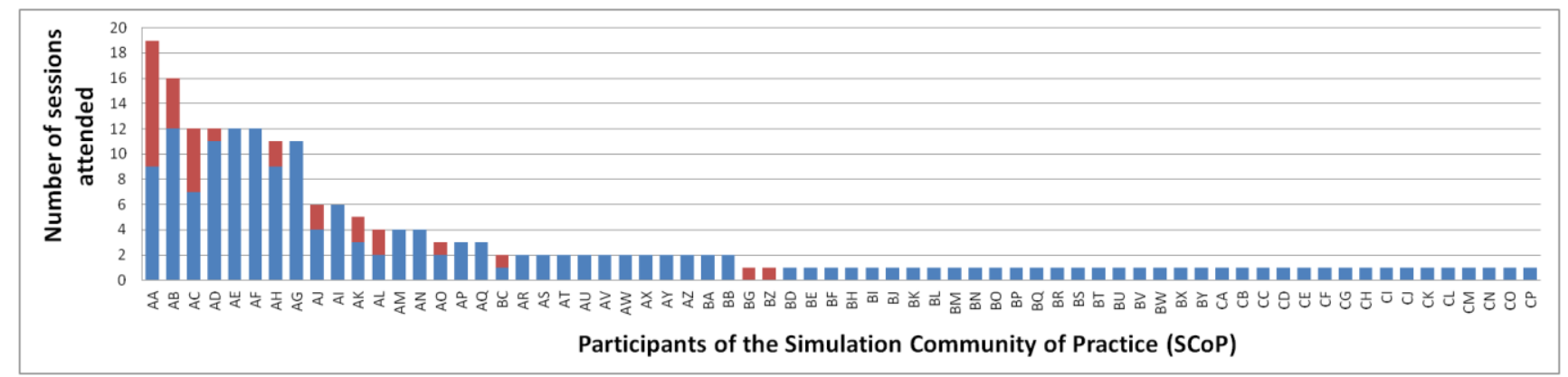

Figure A: 68 people participated in the 20 first sessions of the SCoP. In blue are the number of times each person took part in a session as a participant, and in red as the organizer (or co-organizer) of the session.

\section{Main rules}

All the SCoP sessions have been organized following the framework of the principles as defined at the community's creation in 2007:

$\checkmark$ Sessions are open to all people who are interested;

$\checkmark$ Sessions are optional and flexible (themes, participant presence, ...);

$\checkmark$ Sessions should be focused on the practical rather than academic debate (but the theory is also an interesting subject of study to test, adapt, ...);

$\checkmark$ Sessions may have different forms (demonstration, simulation, discussion, reflection, ...) as long as they provide:

- Interaction and sharing;

- Participation / animation / facilitation;

$\checkmark$ Sessions are evaluated: mutual feedback allows participants to learn about their own behaviors, dynamics of the group and the strengths or the weaknesses of the tested approaches. 